PAPER

\section{Phasor representation for the nonlinear photoacoustic signal}

To cite this article: I E Santosa et al 2017 Eur. J. Phys. 38065803

View the article online for updates and enhancements.

\section{Related content}

- $\frac{\text { Highly sensitive }{ }^{13} \mathrm{C}^{16} \mathrm{O}_{2} \text {-laser }}{\text { photoacoustic detection of ammonia. }}$
$\frac{\text { phosphine and arsine in air }}{\text { V S Starovoitov and S A Trushin }}$
- $\frac{\text { Pulsed photoacoustic system calibration }}{\text { for highly excited molecules }}$
M D Rabasovi, D D Markushev and J
Jovanovi-Kurepa
- Characterization of a precise phase-
$\frac{\text { reading, CO}}{2}$ laser-based photoacoustic
$\frac{\text { spectrometer }}{\text { V Slezak, A Peuriot, N Zajarevich et al. }}$

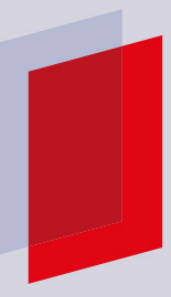

\section{IOP ebooks}

Bringing you innovative digital publishing with leading voices to create your essential collection of books in STEM research. Start exploring the collection - download the first chapter of every title for free. 


\title{
Phasor representation for the nonlinear photoacoustic signal
}

\author{
I E Santosa ${ }^{1,3}$, E J Oetama ${ }^{1}$ and F J M Harren ${ }^{2}$ \\ ${ }^{1}$ Physics Education Study Programme, Sanata Dharma University, Paingan, \\ Maguwohardjo, Sleman, Yogyakarta 55282, Indonesia \\ ${ }^{2}$ Dept of Molecular and Laser Physics, Radboud University Nijmegen, The \\ Netherlands \\ E-mail: edi@usd.ac.id and f.harren@science.ru.nl
}

Received 5 February 2017, revised 18 July 2017

Accepted for publication 4 August 2017

Published 19 October 2017

\begin{abstract}
In $\mathrm{CO}_{2}$ laser-based photoacoustic (PA) systems, $\mathrm{N}_{2}$ takes part in the generation of the PA signal. This process causes the nonlinear relation of the photoacoustic signal to the $\mathrm{CO}_{2}$ concentration. This phenomenon can be explained simply using a phasor diagram. The model leads to the determination of the lag in the PA signal due to $\mathrm{CO}_{2}$ relaxation.
\end{abstract}

Keywords: photoacoustic, phasor, nonlinear

\section{Introduction}

In past years, photoacoustic (PA) phenomena have been investigated and explored extensively. As photoacoustics can be generated in a simple and easy way, its applications can be found in many fields of research [1-6]. Within infrared spectroscopy, photoacoustics is used for the detection of greenhouse gases. Molecular gases, such as $\mathrm{CO}_{2}$ and $\mathrm{H}_{2} \mathrm{O}$, absorb infrared radiation, while the main constituents of air- $\mathrm{N}_{2}$ and $\mathrm{O}_{2}-$ do not [7]. The strength of a PA signal depends on the absorption coefficient of the gas at a specific infrared wavelength, the number of absorbing molecules (i.e. the gas concentration) and the laser power. When multicomponent gas mixtures are used with spectral interference, individual gases contribute to the total PA signal [8]. Photoacoustic generation in gas spectroscopy can be explained as follows: infrared laser radiation is absorbed by the gas sample, and the excited molecules are de-excited via collisions generating heat within a closed volume, causing a pressure increase. Modulating the laser power at a specific audio frequency causes pressure fluctuations, or a sound, at that frequency.

3 Author to whom any correspondence should be addressed. 
$\mathrm{CO}_{2}$ laser-based photoacoustic spectroscopy is well known to be a powerful tool for measuring low concentrations of gases with high sensitivity down to the ppbv level (ppbv, parts per billion volume mixing, $1: 10^{9}$ ) [6]. Nevertheless, special conditions should be considered if the sample also contains $\mathrm{CO}_{2}$ and $\mathrm{N}_{2}$ gas. In contrast to what was published by Fukuhara et al [7], $\mathrm{N}_{2}$ takes part in the generation of the PA signal. In the latter case, kinetic cooling causes the PA signal to lag in phase when applying laser amplitude modulation. In specific conditions, the amplitude of the PA signal decreases instead of increasing with the increasing $\mathrm{CO}_{2}$ concentration [9-11]; this behaviour has been modelled in detail and is used for measuring ammonia [10] and ethylene [11] in mixtures of $\mathrm{H}_{2} \mathrm{O}, \mathrm{CO}_{2}$ and $\mathrm{N}_{2}$.

To model this for pedagogical purposes we use a superposition of two waves with the same frequency but a different phase. Now, with a simple basic calculation, the role of $\mathrm{N}_{2}$ on the $\mathrm{CO}_{2}$ relaxation mechanism can be explained for the generation of the nonlinear PA signal. The experiment can be performed using a continuous wave $\mathrm{CO}_{2}$ laser, a lock-in amplifier and detectors for the laser power and the acoustic signal, which are available in the senior laboratory. This will provide a useful example of phase-sensitive signal detection.

\section{Theory}

\subsection{Brief review of kinetic cooling}

If the laser frequency is tuned to a rotational-vibrational transition within a molecular gas sample, part of the laser beam is absorbed. It is preferable for the excited molecules to release their energy via nonradiative decay. Within the infrared wavelength region, the radiative lifetime for excited molecules is long-much longer than nonradiative decay via collisions at atmospheric pressures. During collisions with other molecules, the excited molecules transfer their excitation energy to the translational energy of the collision partners, resulting in an increase in the temperature. Within a closed volume, the latter is accompanied by an increase in pressure. When modulating the absorption by laser radiation, using frequency modulation or amplitude modulation, the pressure inside the gas absorption cell thus varies periodically and can be detected by a microphone. In general, the microphone signal is linearly proportional to the laser power, the gas concentration (at low concentrations) and the absorption coefficient. Each molecule in the sample will contribute to the generation of the total photoacoustic signal [8].

When a $\mathrm{CO}_{2}$ laser-based photoacoustic system is used to analyse a mixture of ethylene $\left(\mathrm{C}_{2} \mathrm{H}_{4}\right), \mathrm{H}_{2} \mathrm{O}$ and $\mathrm{CO}_{2}$ in $\mathrm{N}_{2}$, there can be a nonlinear relation between the PA signal (amplitude and phase) with the $\mathrm{CO}_{2}$ concentration [11]. At $\mathrm{CO}_{2}$ laser radiation wavelengths, all three gases $\left(\mathrm{C}_{2} \mathrm{H}_{4}, \mathrm{H}_{2} \mathrm{O}\right.$ and $\left.\mathrm{CO}_{2}\right)$ absorb radiation. The de-excitation of the excited levels of $\mathrm{C}_{2} \mathrm{H}_{4}$ and $\mathrm{H}_{2} \mathrm{O}$ is fast and happens via internal relaxation and collisions with other molecules. For excited ro-vibrational levels in $\mathrm{CO}_{2}$, due to the near resonance with the vibrational level of $\mathrm{N}_{2}$ and the high quantity of $\mathrm{N}_{2}$ present in normal air, there is a vibrational energy exchange between $\mathrm{CO}_{2}$ and $\mathrm{N}_{2} . \mathrm{N}_{2}$ will be excited at its first vibrational level and $\mathrm{CO}_{2}$ will be de-excited to the ground state. The first vibrational level of $\mathrm{N}_{2}$ is known to have a long de-excitation lifetime and will be de-excited only on a millisecond timescale (at atmospheric pressure). The internal redistribution within $\mathrm{CO}_{2}$ molecules is fast (via collisions) compared to the rate within the $\mathrm{N}_{2}$. The net result leads to an initial cooling of the gas sample and is therefore known as the kinetic cooling effect [11]. The amplitude and the phase of the PA signal that are then found not only depend on the absorption coefficient and concentration of $\mathrm{C}_{2} \mathrm{H}_{4}, \mathrm{H}_{2} \mathrm{O}$ and $\mathrm{CO}_{2}$, but also on the amount of excitation in the $\mathrm{N}_{2}$ molecules. 


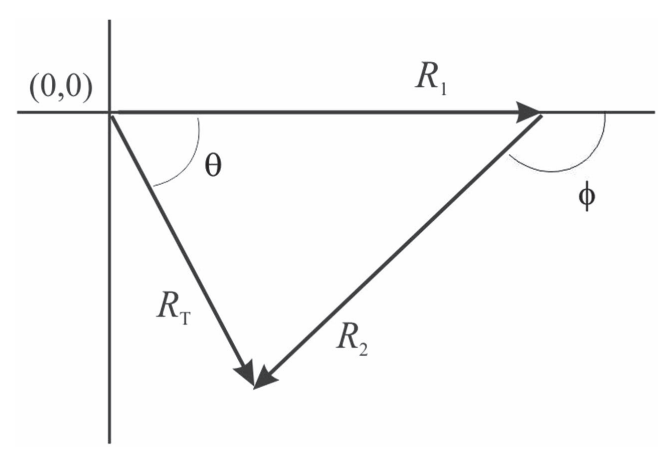

Figure 1. The phasor representation of two photoacoustic signals. The in-phase signal $\left(R_{1}\right)$ is generated by $\mathrm{H}_{2} \mathrm{O}$ and $\mathrm{C}_{2} \mathrm{H}_{4}$, while the $\mathrm{PA}$ signal originating from the $\mathrm{CO}_{2}\left(R_{2}\right)$ has phase $\phi$. The superposition gives $\left(R_{\mathrm{T}}\right)$ with phase $\theta$.

\subsection{Phasor representation}

Here we propose a simple mechanism to show the effect of kinetic cooling. For a single molecule that has fast relaxation, the PA signal is in phase with the laser modulation. If the frequency of laser modulation is $\omega$, this in-phase PA signal is given by

$$
S=R \exp (\mathrm{i} \varpi t)
$$

in which $S$ is the normalized photoacoustic signal, i.e. the ratio of the microphone signal and the laser power, and $R$ is the product of the cell constant (the acoustic cell efficiency of bringing acoustic waves to the microphone), the wavelength-dependent absorption coefficient and the concentration of the absorbing molecular species.

In a mixture of $\mathrm{H}_{2} \mathrm{O}, \mathrm{C}_{2} \mathrm{H}_{4}, \mathrm{CO}_{2}$ and $\mathrm{N}_{2}$, the first three gases are excited simultaneously via the absorption of radiation. During de-excitation, the relaxation of $\mathrm{H}_{2} \mathrm{O}$ and $\mathrm{C}_{2} \mathrm{H}_{4}$ molecules is fast, resulting in a PA signal $\left(S_{1}\right)$ that is in phase with the laser modulation:

$$
S_{1}=R_{1} \exp (\mathrm{i} \varpi t) \text {. }
$$

Next to this, the internal relaxation of the excited $\mathrm{CO}_{2}$ levels also generates an in-phase PA signal. However, part of the excited energy within $\mathrm{CO}_{2}$ is transferred via collisions to excite the $\mathrm{N}_{2}$. The relaxation of the vibrational excited level in the $\mathrm{N}_{2}$ is long and causes a kinetic cooling effect. Due to its slow relaxation, the generated PA signal is delayed and shifts in phase relative to the laser modulation. Therefore, the total PA signal originating from the excitation of $\mathrm{CO}_{2}$ has a phase difference $\phi$ :

$$
S_{2}=R_{2} \exp (\mathrm{i}(\varpi t+\phi))
$$

Its phase shift now depends on the concentrations of $\mathrm{H}_{2} \mathrm{O}$ and $\mathrm{CO}_{2}$ molecules and can vary by up to $180^{\circ}$ [10]. The superposition of the signals resulting from the in-phase (equation (2)) and out-of-phase (equation (3)) signals results in a total signal $S_{\mathrm{T}}$ with an amplitude $R_{\mathrm{T}}$ and a phase $\theta$ given by equation (4):

$$
S_{\mathrm{T}}=R_{\mathrm{T}} \exp (\mathrm{i}(\varpi t+\theta)) \text {. }
$$

Its phasor representation is depicted in figure 1 [12-14]. The PA signal $S_{1}$ is in phase with the laser modulation; the phasor is represented by its amplitude $R_{1}$ along the horizontal axis. The phasor for the second PA signal $S_{2}$, is represented by its amplitude $R_{2}$ and its phase $\phi$. The PA signal $S_{2}$ lags behind the laser modulation and therefore its phase is negative. These phasors are added vectorially to find the phasor of the total PA signal $S_{\mathrm{T}}$ that is represented by its 


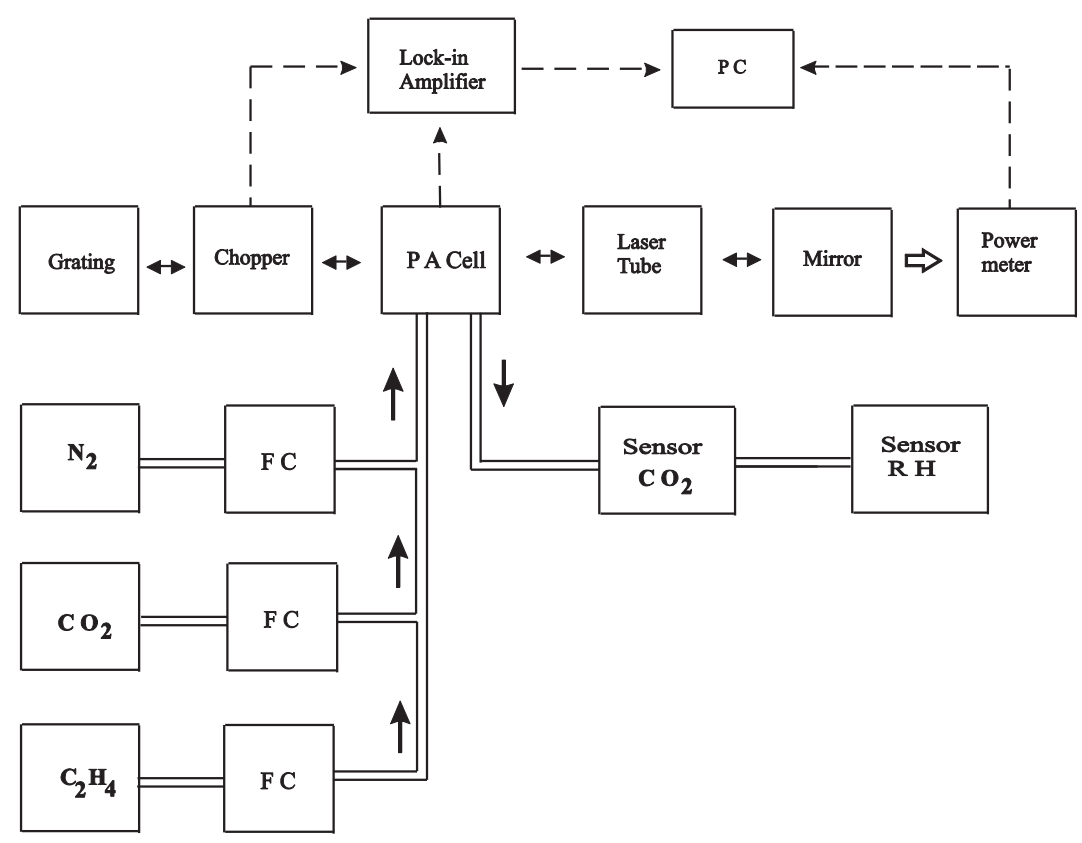

Figure 2. The experimental intracavity photoacoustic set-up. The laser cavity is between the mirror and the grating, in which the laser discharge tube is placed for the gain, the PA cell and the chopper to modulate the laser intensity. The gas mixture entering the PA cell originates from compressed gas bottles and flow controllers (FC) to make mixtures of various concentrations. The $\mathrm{CO}_{2}$ and water vapour concentration are independently measured with sensors.

amplitude $R_{\mathrm{T}}$ and its phase $\theta$. Figure 1 shows that $\theta$ is also negative. The horizontal and vertical components of this total PA signal are $R_{\mathrm{T}} \cos \theta$ and $R_{\mathrm{T}} \sin \theta$.

When the amplitudes from the first photoacoustic signals are kept constant $\left(R_{1}\right.$ is constant), which means that the concentrations of $\mathrm{H}_{2} \mathrm{O}$ and $\mathrm{C}_{2} \mathrm{H}_{4}$ are unchanged, the total PA signal (amplitude $R_{\mathrm{T}}$ and phase $\theta$ ) can depend on the amplitude resulting from the $\mathrm{CO}_{2}$ concentration. An increase in the $\mathrm{CO}_{2}$ concentration causes a longer $R_{2}$ vector. This is followed by an increase (regardless of the negative sign) in $\theta$. To begin with, $R_{\mathrm{T}}$ will decrease, and then at a certain condition it will increase. A minimum of $R_{\mathrm{T}}$ occurs when $R_{\mathrm{T}}$ and $R_{2}$ are perpendicular. In this case its phase $\left(\theta_{\mathrm{m}}\right)$ follows

$$
\theta_{\mathrm{m}}=\phi-90^{\circ} \text {. }
$$

For a constant $R_{1}$ the contribution of the second PA signal originating from $\mathrm{CO}_{2}$ excitation (amplitude $R_{2}$ and phase $\phi$ ) can be extracted by measuring the amplitude of the total PA signal $R_{\mathrm{T}}$ and its phase $\theta$. The phase $\phi$ can be determined from the components of the total signal, $R_{\mathrm{T}} \cos \theta$ and $R_{\mathrm{T}} \sin \theta$, respectively. This will be discussed in section 4 .

\section{Experiment}

The experimental set-up is depicted in figure 2. The continuous wave $\mathrm{CO}_{2}$ laser consists of a grating (for line tunability over the $\mathrm{CO}_{2}$ laser lines), a gas discharge tube for the gain and an outcoupling mirror. The laser power is measured with a power meter. To generate the 
Table 1. Four experiments were performed (a, b, c, d) at two different $\mathrm{CO}_{2}$ laser lines. In each experiment, the $\mathrm{CO}_{2}$ concentration was varied between $350-5000 \mathrm{ppmv}$.

\begin{tabular}{cc}
\hline \multicolumn{3}{c}{$\mathrm{CO}_{2}$ laser line } \\
\hline $10 \mathrm{P} 20$ & $10 \mathrm{P} 14$ \\
a. $\mathrm{H}_{2} \mathrm{O}:(10.0 \pm 0.5) \%$ & b. $\mathrm{H}_{2} \mathrm{O}:(9.8 \pm 0.3) \%$ \\
c. $\mathrm{H}_{2} \mathrm{O}:(9.8 \pm 0.5) \%$ & d. $\mathrm{H}_{2} \mathrm{O}:(11.9 \pm 0.3) \%$ \\
$\mathrm{C}_{2} \mathrm{H}_{4}: 1 \mathrm{ppmv}$ & $\mathrm{C}_{2} \mathrm{H}_{4}: 1 \mathrm{ppmv}$ \\
\hline
\end{tabular}

photoacoustic signal via the amplitude modulation of the laser power a chopper is used. The modulation frequency of the chopper is $1749 \mathrm{~Hz}$, i.e. the resonance frequency of the photoacoustic cell (PA cell). Here the PA cell is placed inside the laser cavity to enhance the sensitivity for gas detection, due to the high intracavity laser power [15]. The intracavity laser power depends on the $\mathrm{CO}_{2}$ laser line, i.e. around $20 \mathrm{~W}$. An electret microphone detects the pressure changes in the photoacoustic cell. The sensitivity of this microphone is $10 \mathrm{mV} \mathrm{Pa}$. To enhance the photoacoustic signal and to reject all other acoustic sound from the environment, a lock-in amplifier (7220 DSP Lock-in Amplifier, EG\&G Instruments) is used. The modulation signal from the chopper is used as a reference for the lock-in amplifier. It only amplifies (phase sensitive) at the modulation frequency within a bandwidth of $1 \mathrm{~Hz}$ and rejects all other acoustic and electronic noise. A personal computer (PC) provides data acquisition and controls the experiment.

The gas mixture containing $\mathrm{N}_{2}, \mathrm{CO}_{2}$ and $\mathrm{C}_{2} \mathrm{H}_{4}$ is fed to the PA cell through flow controllers (FC) to generate mixtures with various $\mathrm{CO}_{2}$ concentrations. The mixture also contains traces of $\mathrm{H}_{2} \mathrm{O}$. To measure the $\mathrm{CO}_{2}$ concentration independently, a $\mathrm{CO}_{2}$ sensor $\left(\mathrm{CO}_{2}\right.$-BTA, Vernier) is placed at the outlet of the PA cell. A relative humidity $(\mathrm{RH})$ sensor (RH-BTA, Vernier) is used to monitor the water vapour concentration. The room temperature is also monitored continuously. These sensors, i.e. the $\mathrm{CO}_{2}$ sensor, the $\mathrm{RH}$ sensor and the temperature probe (STS-BTA, Vernier), are connected to a Vernier interface [16]. The data is collected using Vernier Logger Pro software.

Various gas mixing experiments were performed to investigate the effect of $\mathrm{CO}_{2}$ concentration on the PA signal. Various gas mixing concentrations of $\mathrm{N}_{2}, \mathrm{CO}_{2}$ and $\mathrm{C}_{2} \mathrm{H}_{4}$ were achieved by adjusting the flow controllers. The main gas constituent was $\mathrm{N}_{2}$, while $\mathrm{CO}_{2}$ and $\mathrm{C}_{2} \mathrm{H}_{4}$ were at trace gas levels. The photoacoustic effect with a varying amplitude and phase was studied by performing measurements on two different $\mathrm{CO}_{2}$ laser lines (wavenumbers), i.e. 10P20 $\left(944.1940 \mathrm{~cm}^{-1}\right)$ and 10P14 $\left(949.4793 \mathrm{~cm}^{-1}\right) \mathrm{CO}_{2}$ laser lines. At these laser lines, the absorption coefficients of $\mathrm{C}_{2} \mathrm{H}_{4}$ are $1.84 \mathrm{~atm}^{-1} \mathrm{~cm}^{-1}$ and $30.4 \mathrm{~atm}^{-1} \mathrm{~cm}^{-1}$, respectively [17]. Different combinations of gas mixtures and laser lines used in the experiment are presented in table 1 . In this table, the water vapour concentration was calculated from the relative humidity sensor, the temperature during the experiment and the available partial pressure data [18]. In each condition $(\mathrm{a}, \mathrm{b}, \mathrm{c}, \mathrm{d})$ the $\mathrm{CO}_{2}$ concentration was varied in a range of 350-5000 ppm. In the $\mathrm{C}_{2} \mathrm{H}_{4}$-containing mixture, the $\mathrm{C}_{2} \mathrm{H}_{4}$ concentration was kept constant (1 ppmv).

Due to the fast relaxation, the PA signal originating from $\mathrm{H}_{2} \mathrm{O}$ and $\mathrm{C}_{2} \mathrm{H}_{4}$ is only in phase with the laser modulation. At the start of the experiment, the phase of this PA signal was set to zero, indicating it to be the in-phase signal. The PA signal and its phase, as well as the laser 

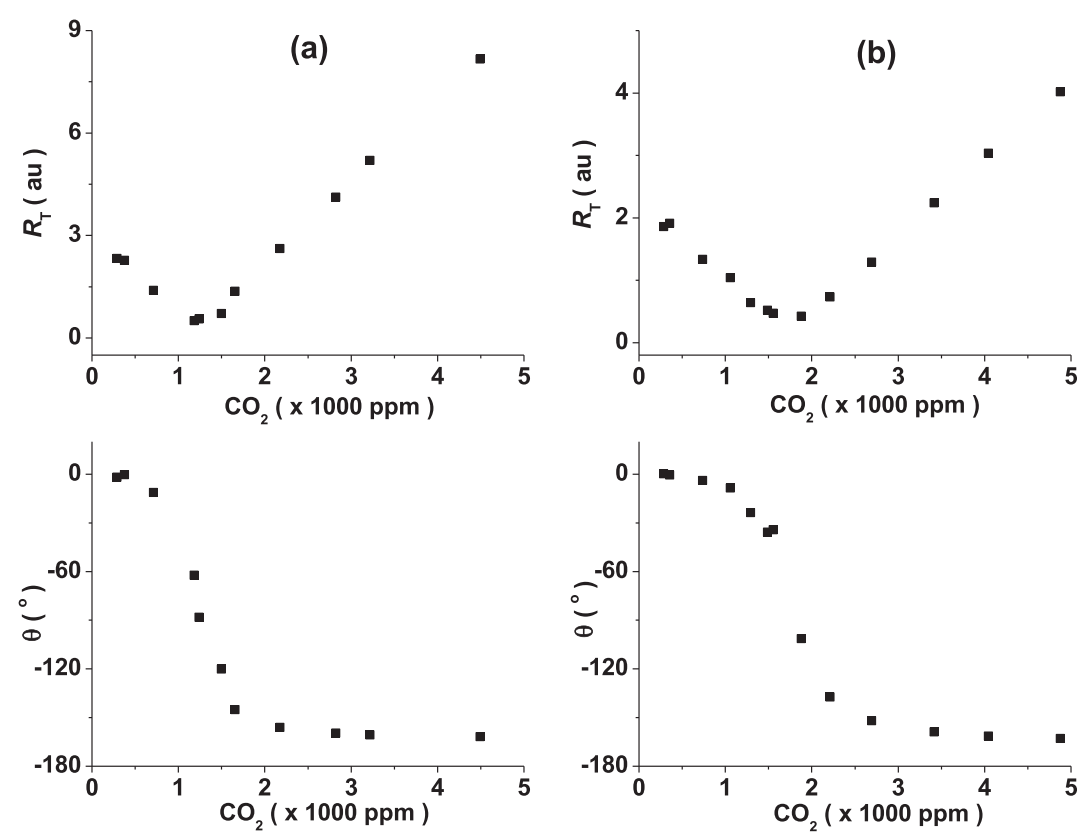

Figure 3. The amplitude $\left(R_{\mathrm{T}}\right)$ and the phase $(\theta)$ of the PA signal as a function of the $\mathrm{CO}_{2}$ concentration. The measurements were carried out at the $10 \mathrm{P} 20$ laser line. (a) Left panels: amplitude and phase of the PA signal from gas mixtures consisting of $\mathrm{N}_{2}, \mathrm{H}_{2} \mathrm{O}$ and $\mathrm{CO}_{2}$. (b) Right panels: $\mathrm{N}_{2}, \mathrm{H}_{2} \mathrm{O}, \mathrm{CO}_{2}$ and $\mathrm{C}_{2} \mathrm{H}_{4}$ mixtures.

power, were recorded using a PC. The unit of normalized PA signal was an arbitrary unit (a.u.). The results are presented in figures 3 and 4 .

Figure 3 shows the amplitude of the normalized PA signal and its phase measured at the 10P20 laser line. The PA signal comes from traces of water vapour in the $\mathrm{N}_{2}$ and from $\mathrm{CO}_{2}$ (figure 3(a)). By increasing the $\mathrm{CO}_{2}$ concentration, the PA signal amplitude first decreases and then subsequently increases following the $\mathrm{CO}_{2}$ concentration. At the minimum, a fast change in the phase is observed up to $-160^{\circ}$. The minimum amplitude is found at a concentration of $1200 \mathrm{ppmv} \mathrm{CO}_{2}$. Similar behaviour is demonstrated in figure 3(b) upon adding to the $\mathrm{C}_{2} \mathrm{H}_{4}$ gas mixture.

The amplitude and phase of the normalized PA signal at the 10P14 laser line are depicted in figure 4. For a mixture of $\mathrm{N}_{2}, \mathrm{H}_{2} \mathrm{O}$ and $\mathrm{CO}_{2}$ (figure 4(a), left panel) the behaviour is similar to the measurements at the 10P20 laser line. There is a minimum of amplitude and the phase changes up to $-160^{\circ}$. In figure $4(\mathrm{~b})$, by adding $\mathrm{C}_{2} \mathrm{H}_{4}$, the photoacoustic amplitude gains about a factor of two. Due to the increase in $\mathrm{CO}_{2}$ concentration a decrease in the PA signal is observed, but no minimum PA signal is reached. The observed phase change is relatively small, with a maximum phase change of only $-10^{\circ}$.

\section{Discussion}

Using a $\mathrm{CO}_{2}$ laser-based photoacoustic detection system, it was found that in a mixture with $\mathrm{N}_{2}$ and $\mathrm{CO}_{2}$, the PA signal changes nonlinearly. This phenomenon can be explained using a phasor diagram, as illustrated in figure 1. The effect of changing $\mathrm{CO}_{2}$ concentrations is demonstrated by the change of $\theta$. Figure 1 shows that $\theta$ depends on the proportionality 

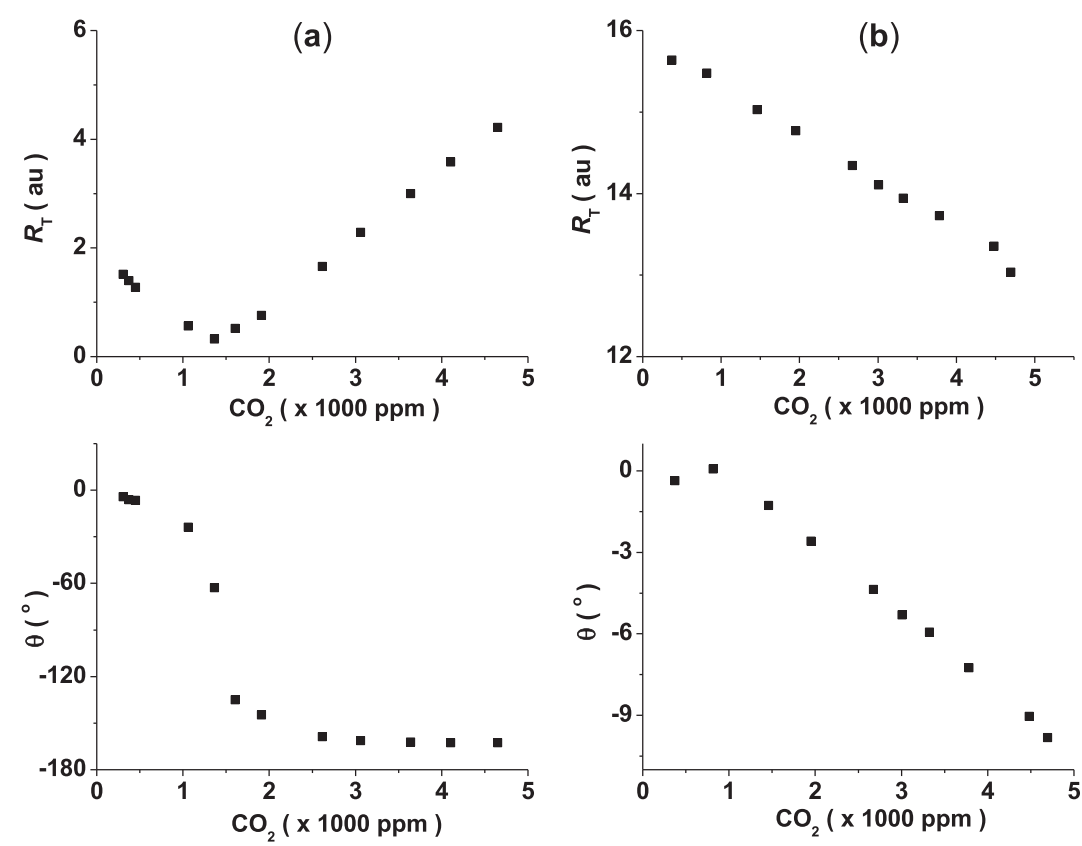

Figure 4. The amplitude $\left(R_{\mathrm{T}}\right)$ and the phase $(\theta)$ of the PA signal as a function of the $\mathrm{CO}_{2}$ concentration. The measurements were carried out on the 10P14 laser line. (a) Left panels: amplitude and phase of the PA signal from the gas mixtures consisting of $\mathrm{N}_{2}$, $\mathrm{H}_{2} \mathrm{O}$ and $\mathrm{CO}_{2}$. (b) Right panels: $\mathrm{N}_{2}, \mathrm{H}_{2} \mathrm{O}, \mathrm{CO}_{2}$ and $\mathrm{C}_{2} \mathrm{H}_{4}$ mixtures. Notice the scales on the panels are not the same.

between the in-phase signal $\left(R_{1}\right)$ and the signal originating from the relaxation of $\mathrm{CO}_{2}\left(R_{2}\right)$. This observation is more prominent if the in-phase signal is relatively small. On the other hand, for a large in-phase signal the change in $\theta$ is small.

Phase changes up to $-160^{\circ}$ are observed at the $10 \mathrm{P} 20$ laser line in which the total inphase signal is small. For this measurement, the in-phase signal is generated by water vapour (figure 3(a)) and by water vapour and $\mathrm{C}_{2} \mathrm{H}_{4}$ (figure 3(b)). The absorption coefficient of $\mathrm{C}_{2} \mathrm{H}_{4}$ in this $10 \mathrm{P} 20$ laser line is small. Therefore, the added $\mathrm{C}_{2} \mathrm{H}_{4}$ does not increase the in-phase signal significantly. The measurements at the 10P14 laser line show different behaviour. For a mixture of $\mathrm{N}_{2}, \mathrm{H}_{2} \mathrm{O}$ and $\mathrm{CO}_{2}$ the phase also changes up to $-160^{\circ}$ (see figure 4(a)). This is caused by a small, in-phase signal from the water vapour. Adding $\mathrm{C}_{2} \mathrm{H}_{4}$ (figure $4(\mathrm{~b})$ ) using the 10P14 laser lines gives only a small phase change in $\theta$ around $-10^{\circ}$. This small phase change is due to the dominant in-phase signal generated by $\mathrm{C}_{2} \mathrm{H}_{4}$. At this $\mathrm{CO}_{2}$ laser line $\mathrm{C}_{2} \mathrm{H}_{4}$ has a strong absorption coefficient.

In the first experiment, figure $3(\mathrm{a})$, a minimum $R_{\mathrm{T}}$ is observed for a $\theta$ between $62^{\circ}$ and $88^{\circ}$. For the same concentration of water vapour (and $\left.\mathrm{C}_{2} \mathrm{H}_{4}\right), R_{1}$ is constant. An increase in the $\mathrm{CO}_{2}$ concentration leads to an increase in the amplitude $R_{2}$ and causes an increase in $\theta$. It is clear that if $\theta$ increases then $R_{\mathrm{T}}$ first decreases. When the phasor $R_{\mathrm{T}}$ and $R_{2}$ are perpendicular, $R_{\mathrm{T}}$ becomes a minimum. A similar situation can be observed in figures $3(\mathrm{~b})$ and $4(\mathrm{a})$. In figure 4(b), the in-phase PA signal is from $\mathrm{H}_{2} \mathrm{O}$ and $\mathrm{C}_{2} \mathrm{H}_{4}$. Due to its strong absorption, this in-phase PA signal is much higher than the out-of-phase PA signal, and as such the change in $\theta$ is small. An increase in the $\mathrm{CO}_{2}$ concentration leads to a decrease in $R_{\mathrm{T}}$, with no minimum value, since that value cannot be reached. 


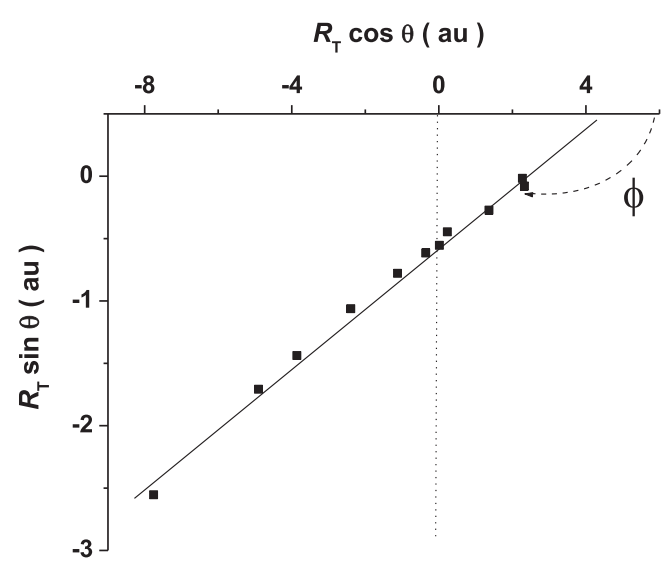

Figure 5. The relation of the components of the total PA signal, i.e. $R_{\mathrm{T}} \sin \theta$ and $R_{\mathrm{T}}$ $\cos \theta$, for various $\mathrm{CO}_{2}$ concentrations. The measurement was carried out on the $10 \mathrm{P} 20$ laser line. The gas mixture consists of $\mathrm{N}_{2}, \mathrm{H}_{2} \mathrm{O}$ and $\mathrm{CO}_{2}$. The dashed line is an indication of the vertical axis that goes through the origin $(0,0)$ in figure 1 . The solid line is a linear fit to obtain the phase $\phi$.

Table 2. The phase $(\phi)$ of phasor $R_{2}$, the calculated and observed phase $\left(\theta_{\mathrm{m}}\right)$ of the phasor $R_{\mathrm{T}}$.

\begin{tabular}{lccc}
\hline & & \multicolumn{2}{c}{$\theta_{\mathrm{m}}$} \\
\cline { 3 - 4 } Source & $\phi$ & Calculated & Observed \\
\hline Figure 3(a) & $(-166 \pm 2)^{\circ}$ & $(-76 \pm 2)^{\circ}$ & $(-71 \pm 8)^{\circ}$ \\
Figure 3(b) & $(-168 \pm 2)^{\circ}$ & $(-78 \pm 2)^{\circ}$ & $(-70 \pm 5)^{\circ}$ \\
Figure 4(a) & $(-169 \pm 2)^{\circ}$ & $(-79 \pm 2)^{\circ}$ & $(-72 \pm 5)^{\circ}$ \\
\hline
\end{tabular}

To identify the contribution of $\mathrm{CO}_{2}$ on the total PA signal for each $\mathrm{CO}_{2}$ concentration, we decompose the total signal (see figure 1) into two parts, i.e. $R_{\mathrm{T}} \cos \theta$ and $R_{\mathrm{T}} \sin \theta$. These two parts can be obtained from the $R_{\mathrm{T}}$ and $\theta$ of each point presented in figures 3 and 4 . In accordance with figure 1, the coordinate of the tip of the phasor of the total PA signal is $R_{\mathrm{T}}$ $\cos \theta, R_{\mathrm{T}} \sin \theta$. Using the data presented in figure 3(a), these coordinates are depicted as points for various $\mathrm{CO}_{2}$ concentrations in figure 5 .

The amplitudes of the total PA signal $\left(R_{\mathrm{T}}\right)$ can be traced from the origin to these points. A straight line through these points shows the direction of the phasor $R_{2}$ for different $\mathrm{CO}_{2}$ concentrations. This phasor represents the PA signal originating from the relaxation of the $\mathrm{CO}_{2}$ in the mixture of $\mathrm{N}_{2}, \mathrm{H}_{2} \mathrm{O}$ and $\mathrm{CO}_{2}$. It also shows the constant $\phi$ form equation (3) and figure 1. From the linear fit in figure $5, \phi$ can be obtained, i.e. $\left(-166^{\circ} \pm 1^{\circ}\right)$. For different conditions (mixtures and laser lines), the obtained $\phi$ is presented in table 2 .

The minimum of $R_{\mathrm{T}}$ will be found when the phasors $R_{\mathrm{T}}$ and $R_{2}$ are perpendicular. In this condition, the phase $\left(\theta_{\mathrm{m}}\right)$ of phasor $R_{\mathrm{T}}$ can be calculated using equation (5). This $\theta_{\mathrm{m}}$ can also be observed directly in figures 3(a), (b) and 4(a). The observed $\theta_{\mathrm{m}}$ can be determined from the interpolation on these figures. The calculated and observed $\theta_{\mathrm{m}}$ are presented in table 2 . It can be seen that the calculated $\theta_{\mathrm{m}}$ is the same as the observed $\theta_{\mathrm{m}}$.

The energy absorbed by the $\mathrm{CO}_{2}$ molecules is used to generate the PA signal directly, and also to vibrationally excite the $\mathrm{N}_{2}$. Subsequently, the relaxation of the excited $\mathrm{N}_{2}$ also 


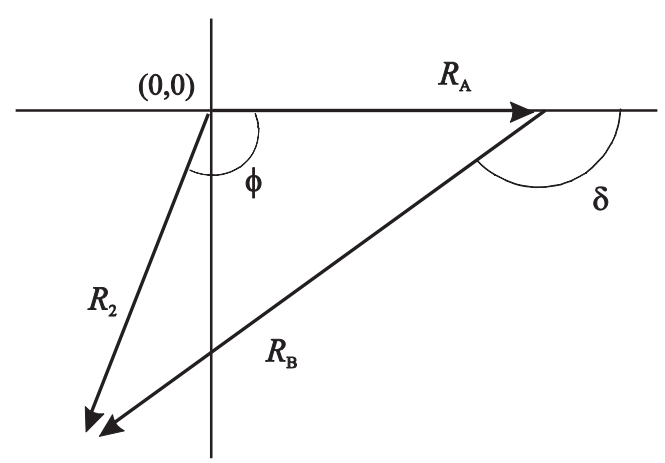

Figure 6. The phasor representation of two photoacoustic signals originating from the excitation of $\mathrm{CO}_{2}$ only. The first in-phase signal $\left(R_{\mathrm{A}}\right)$ is generated by the direct relaxation of excited $\mathrm{CO}_{2}$. The second signal $\left(R_{\mathrm{B}}, \delta\right)$ is generated by the relaxation of excited $\mathrm{N}_{2}$. The total PA signal originating from the $\mathrm{CO}_{2}$ excitation is therefore represented by the amplitude $R_{2}$ and phase $\phi$.

generates a PA signal, but on a longer timescale. The direct PA signal from the $\mathrm{CO}_{2}\left(R_{\mathrm{A}}\right)$ is in phase with the laser modulation (figure 6). The out-of-phase PA signal is caused by the slow relaxation of $\mathrm{N}_{2}\left(R_{\mathrm{B}}\right)$ with the phase $(\delta)$. Therefore, the total PA signal $\left(R_{2}\right)$ originating from the $\mathrm{CO}_{2}$ excitation shows a phase $(\phi)$ to the laser modulation. This situation is similar to figure 1 , however it is now only for $\mathrm{CO}_{2}$. The amplitudes of both signals $\left(R_{\mathrm{A}}\right.$ and $\left.R_{\mathrm{B}}\right)$ depend on the $\mathrm{CO}_{2}$ concentration, and are proportional to each other. The relaxation time of excited $\mathrm{N}_{2}$ depends on the relaxation times for the vibrational-translational energy exchange between molecules in the gas sample $[10,11]$. Therefore for the same conditions $\delta$ is expected to be constant. As a result, the amplitude $R_{2}$ is affected by the $\mathrm{CO}_{2}$ concentration, while $\phi$ is independent of it.

The phase $(\phi)$ was found to have a value of more than $90^{\circ}$, with $R_{\mathrm{B}}$ longer than $R_{\mathrm{A}}$. This indicates that the relaxation of the excited $\mathrm{CO}_{2}$ is more efficient in transferring energy to $\mathrm{N}_{2}$.

The proposed simple model is adequate for explaining the effect of kinetic cooling. This is based on the approximation that $\delta$, due to the relaxation of excited $\mathrm{N}_{2}$, is constant and independent of the $\mathrm{CO}_{2}$ concentration. A closer inspection of figure 5 shows a small deviation from the straight line. This nonlinear situation reveals the $\mathrm{CO}_{2}$ dependence on the phase $\delta$. The source of this phase change is the relaxation time of the excited $\mathrm{N}_{2}$, which also depends on the $\mathrm{CO}_{2}$ concentration [9-11].

\section{Conclusion}

The presence of vibrationally excited $\mathrm{CO}_{2}$ in a gas sample exhibits a special condition for the generation of the PA signal. During de-excitation, $\mathrm{CO}_{2}$ transfers its energy to vibrationally excite $\mathrm{N}_{2}$, causing a kinetic cooling effect. This mechanism leads to the nonlinear dependence of the PA signal amplitude on the $\mathrm{CO}_{2}$ concentration, as well as the phase changes. The effect of kinetic cooling on the amplitude and phase of the PA signal is prominent, if the photoacoustic signal originating from $\mathrm{CO}_{2}$ excitation is comparable with the signal from other molecules in the gas sample. 


\section{Acknowledgments}

The authors thank A Bima Windura for his technical support. The authors would like to thank the reviewers for their thoughtful comments and for suggesting improvements.

\section{References}

[1] Rush W F and Heubler J E 1982 Photoacoustic effect demonstration Am. J. Phys. 50669

[2] Euler M, Niemann K and Müller A 2000 Hearing light Phys. Teach. 38 356-8

[3] Euler M 2001 Hands-on resonance-enhanced photoacoustic detection Phys. Teach. 39 406-9

[4] Zhu Z, Du L, Zhang Y, Wang S, Zhou H and Gao W 2015 Hearing light from an incandescent bulb Eur. J. Phys. 36 1-9

[5] Nikitichev D I, Xia W, Hill E, Mosse C A, Perkins T, Konyn K, Ourselin S, Desjardins A E and Vercauteren T 2016 Music-of-light stethoscope: a demonstration of the photoacoustic effect Phys. Educ. 51 1-9

[6] Harren F J M, Mandon J and Cristescu S M 2012 Photoacoustic spectroscopy in trace gas monitoring Encyclopedia of Analytical Chemistry ed R A Meyers (Chichester: J. Wiley) pp 1-24

[7] Fukuhara A, Kaneko F and Ogawa N 2012 Simple model of a photoacoustic system as a CR circuit Eur. J. Phys. 33 623-35

[8] Zharov V P and Letokhov V S 1986 Laser Optoacoustic Spectroscopy (Berlin: Springer Verlag)

[9] Hammerich M, Olafsson A and Henningsen J 1992 Photoacoustic study of kinetic cooling Chem. Phys. 163 173-8

[10] Rooth R A, Verhage A J L and Wouters L W 1990 Photoacoustic measurement of ammonia in the atmosphere: influence of water vapour and carbon dioxide Appl. Opt. 29 3643-52

[11] Moeckli M A, Hilbes C and Sigrist M W 1998 Photoacoustic multicomponent gas analysis using a Levenberg-Marquardt fitting algorithm Appl. Phys. B 67 449-58

[12] Serway R A and Vuille C 2012 College Physics 9th edn (Boston MA: Brooks/Cole) p 730

[13] Young H D 2012 Sears \& Zemansky's College Physics 9th edn (San Francisco CA: AddisonWesley) pp 735-6

[14] Rossing T D and Fletcher N H 1995 Principles of Vibration and Sound (New York: Springer Verlag) p 7

[15] Harren F J M, Bijnen F G C, Reusss J, Voesenek L A C J and Blom C W P M 1990 Sensitive intracavity photoacoustic measurements with a $\mathrm{CO}_{2}$ waveguide laser Appl. Phys. B 50 137-44

[16] Vernier Software \& Technology, 13979 SW Millikan Way, Beaverton, OR 97005-2886http:// vernier.com/

[17] Brewer R J, Bruce C W and Mater J L 1982 Optoacoustic spectroscopy of $\mathrm{C}_{2} \mathrm{H}_{4}$ at the 9- and $10 \mu \mathrm{m} \mathrm{C}^{12} \mathrm{O}_{2}^{16}$ laser wavelengths Appl. Opt. $214092-100$

[18] Lide D R 1995 CRC Handbook of Chemistry and Physics 76th edn (Boca Raton: CRC Press) pp 6-15 